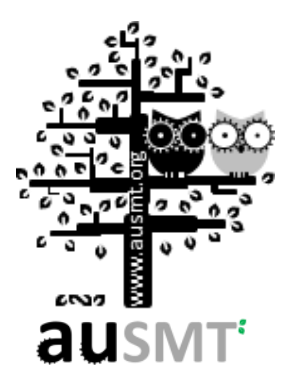

\title{
Trend Analysis on the Automation of the Notebook PC Production Process
}

\section{Chin-Ching Yeh*}

Industrial Economics and Knowledge Center (IEK), Industrial Technology Research Institute (ITRI), Taiwan

(Received 24 July 2012; Published on line 1 September 2012)

*Corresponding author: ccyeh@itri.org.tw

DOI: $10.5875 /$ ausmt.v2i3.153

\begin{abstract}
Notebook PCs are among the Taiwanese electronic products that generate the highest production value and market share. According to the ITRI IEK statistics, the domestic Notebook PC - production value in 2011 was about NT \$2.3 trillion. Of about 200 million notebook PCs in global markets in 2011, Taiwan's notebook PC output accounts for more than $90 \%$ of them, meaning that nine out of every ten notebook PCs in the world are manufactured by Taiwanese companies. For such a large industry with its output value and quantity, the degree of automation in production processes is not high. This means that there is still a great room for the automation of the notebook PC production process, or that the degree of automation of the production process of the laptops cannot be enhanced. This paper presents an analysis of the situation.
\end{abstract}

Keywords: Notebook PC; Automation; Ultrabook; Tablet PC

\section{The gross profit margin for domestic notebook PC OEMs is about 3 to $4 \%$}

According to a study by the Industrial Technology Research Institute's Industrial Economics \& Knowledge center (ITRI IEK), the 2011 domestic notebook PC production value was about 2.3 trillion, as shown in Table 1. It can be expected that the laptop market will continue to grow in the future, but because of the impact of tablet PC sales, the growth rate will decrease to single digits.

The domestic approach to the market has been varied. Several domestic notebook PC original equipment manufacturers (OEMs), such as Quanta and Inventec, were in the notebook PC OEM business type from the outset until now. In addition, two OEMs were separated from original brand manufacturers (OBMs): Wistron was split from Acer, and Pegatron was split from Asus. In addition, Hon Hai entered the notebook PC OEM business only in recent years, and because of the belated undertaking, orders are mainly on laptops for Apple. Some companies direct their business according to their niche markets or develop brand production and OEM at the same time. For such companies, such as CLEVO, MSI, ECS, FIC, and Twinhead, the production scale may not be large, but the gross margin is more rewarding.

There are five OEMs whose revenues of notebook PC manufacturing exceed $50 \%$ of the company's total revenue: $90 \%$ for Compal; $77 \%$ for Inventec; $70 \%$ for Quanta; $60 \%$ for Wistron; and 50\% for Pegatron. In addition to the OBMs and the smaller manufacturers, the five companies' gross margins were about 3 to $4 \%$; the competition is simply intense. In 2011, it was reported that even Flextronics, an internationally-renown electronic manufacturing services (EMS) company, also considered withdrawing from the notebook PC OEM market. This may explain why the notebook PC OEMs nowadays have to develop other OEM products so as to reduce the proportion of the revenue of notebook PC production in the company's total revenue. At present, many notebook PC OEMs have started to increase their production of cloud servers, LCD TVs, game consoles and other products recently becoming popular. 
Table 1. Production value for domestic notebook PC OEMs.

\begin{tabular}{|lllll|}
\hline Company & $\begin{array}{l}2011 \\
\text { Total revenue } \\
\text { (thousand NTD) }\end{array}$ & $\begin{array}{l}\text { Profit Margin } \\
(\%)\end{array}$ & $\begin{array}{l}\text { Notebook PC } \\
(\%)\end{array}$ & $\begin{array}{l}\text { Notebook PC } \\
\text { Revenue } \\
\text { (thousand NTD) }\end{array}$ \\
\hline Compal & $1,060,512,621$ & 3.20 & $70 \%$ & $742,358,835$ \\
\hline Wistron & $585,477,507$ & 3.31 & $90 \%$ & $584,529,756$ \\
\hline Inventec & $338,417,380$ & 3.80 & $60 \%$ & $351,572,759$ \\
\hline Pegatron & $371,712,693$ & 0.61 & $77 \%$ & $260,581,383$ \\
\hline Hon Hai & $2,773,257,916$ & 3.46 & $50 \%$ & $185,856,347$ \\
\hline MSI & $73,316,586$ & 8.20 & $5 \%$ & $138,662,896$ \\
\hline CLEVO & $11,020,446$ & 8.52 & $30 \%$ & $21,994,976$ \\
\hline Total & $5,852,649,302$ & - & $100 \%$ & $11,020,446$ \\
\hline
\end{tabular}

In addition, with Apple's introduction of an ultra-thin notebook PC that is generating skyrocketing sales, coupled with the impact brought by the light, thin, energy-saving properties and integrated service system of the tablet PC, the PC manufacturers have responded by introducing an ultra-thin notebook PC. However, the increase of these new functions poses new challenges for the enhancement of process automation.

\section{Degree of automation of the main production process of notebook PCs is not high}

According to the research and surveys undertaken by ITRI IEK, the manufacturing process of notebook PCs can be divided into four areas, as shown in Figure 1: N1-motherboard processing; N2-liquid crystal display processing; N3-keyboard processing; N4-body assembly.

Using ITRI IEK questionnaires and the actual interviews, the average scores of the amount of automation at each point in the production process have been recorded (statistical averages are presented in a 1-5 scale, with 5 being the highest degree of automation). On the scale, motherboard processing scores 2.18 points, which is the highest degree of automation. The keyboard processing, however, scored only 1.08 points, ranking as the lowest degree of automation.

Chin-Ching Yeh is a Researcher in the Machinery \& System Research Division at Industrial Economics and Knowledge Center. He got his master degree in Industrial Education from National Changhua University of Education, Taiwan. His research topics focus on Tablet PC, TFT LCD, OLED, Flexible Display, Machinery, Robotics, and so on.
For those sub processes among the main process (N1 motherboard processing), surface mount technology SMT (A3) scored 5.0, reaching almost $100 \%$ automation and receiving the highest ranking. Besides this process, the function testing (A11) received 4.4 points, indicating that it is not far off from being fully automated. In the N4 body assembly sub-processes, the average scores for the accelerated aging test (D8) was 4.8 , while the function test (D7) received 3.4, and with the product shipments (D14) at 3.8. These three sub-processes are of higher degree of automation.

\section{Conclusion}

1. Although the domestic notebook PC OEM already accounts for more than $90 \%$ of the global market, the degree of automation in the production processes is not high, scoring 3 or less in average on a 1-5 scale.

2. Some manufacturers' annual output of notebook PCs has exceeded 10 million units. However, because there are too many notebook PC models, the output of a single model is barely more than 50,000 units. Thus, it is not easy to enhance the degree of automation. To increase the degree of automation, the number of product models must be decreased.

3. Currently, SMT, functional testing and other notebook PC production process have undergone relatively higher degrees of automation. SMT is almost $100 \%$ automated, and the automation of testing is close to $80 \%$.

4. Because of commercial confidentiality considerations, OEMs are very sensitive to the disclosure of automation information. 
5. Some of the notebook PC OBMs have the knowhow for production automation. For example, Apple takes over the planning of the production process automation in OEMs; in addition, since the company's product models are relatively few, the degree of automation in OEMs is relatively higher.
6. The wage for Mainland China labor is increasing over recent years. This will also cause manufacturers to enhance the degree of automation.

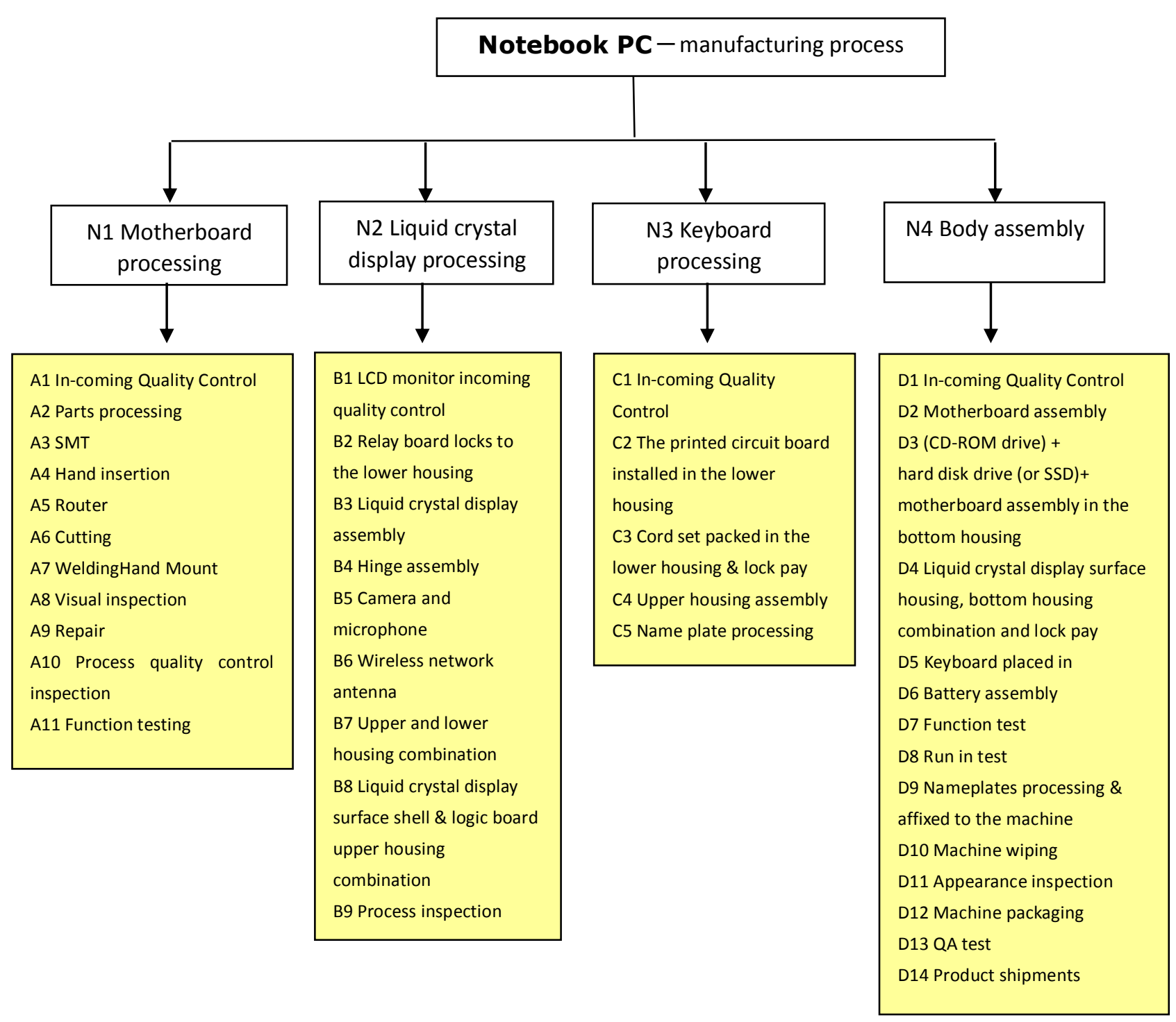

Figure 1. The main production process of notebook PCs. 